\title{
Obtenção e caracterização de anticorpo monoclonal murino anti-fator VIII da coagulação sangüínea
}

\author{
Attainment and characterization of murine monoclonal anti-factor VIII antibodies
}

Rosana Rossi-Ferreira ${ }^{1}$

Elenice Deffune ${ }^{2}$

Izolete Thomazini-Santos ${ }^{3}$

Paulo E. A. Machado ${ }^{4}$

\begin{abstract}
Entre os avanços da engenharia celular e biotecnologia nas últimas décadas, destaca-se a produção de anticorpos monoclonais murinos (AcMm) utilizados no aprimoramento diagnóstico nas rotinas laboratoriais. A produção de fator VIII de alta pureza sempre foi o desejo e a preocupação das indústrias de hemoderivados para tratamento de pacientes portadores de hemofilia A, porém este produto inexiste no Brasil, sendo necessária sua obtenção no mercado internacional a custos elevados. O trabalho tem por objetivo a produção de AcMm anti-fator VIII humano (FVIII ${ }_{H}$ ) através da expansão dos clones e caracterização imunoquímica do anticorpo. Camundongos Balb/c foram imunizados com $\mathrm{FVIII}_{H}$ purificado como também proveniente de crioprecipitado e as células esplênicas dos animais foram fusionadas com células mielomatosas murinas segundo o método descrito por Kohler e Milstein para produção de híbridos em cultura. Foram testados 1.983 híbridos dos quais 105 foram submetidos à clonagem. Destes, 39 obtiveram monoclonalidade e 7 destes clones foram caracterizados através de técnicas de immunoblotting. Foram submetidas à purificação por cromatografia três imunoglobulinas de diferentes classes pertencentes aos clones LAMB1-10A1A4, LAMB1-17A1A1 e LAMB1-24A2A1. A imunoglobulina purificada pertencente ao clone LAMB1-10A1A4 foi adsorvida em coluna de imunoafinidade para purificação de concentrado de FVIII proveniente de crioprecipitado plasmático. Rev. bras. hematol. hemoter. 2006;28(2):97-104.
\end{abstract}

Palavras-chave: Fator VIII; hemofilia; hemoderivados; produtos biotecnológicos.

\section{Introdução}

A hemofilia é uma doença causada pela deficiência do Fator VIII, uma glicoproteína que participa na via intrínseca da coagulação sangüínea e tem como etiologia a herança genética, ligada ao cromossomo $\mathrm{X}$, ocorrendo exclusivamente em homens. A severidade da doença está diretamente relacionada com a extensão da deficiência de FVIII, que é classificada em hemofilia severa, moderada e branda. O tratamento consiste na reposição do Fator VIII através de transfusões sangüíneas.
Em 1959, Pool \& Robinson, ${ }^{1}$ utilizando o método de Cohnn ${ }^{2}$ na produção de sedimento insolúvel (crioprecipitado) através de processos de congelamento e descongelamento lento, purificaram as proteínas plasmáticas com atividade anti-hemofílica. O crioprecipitado foi utilizado na terapia da hemofilia até a início da década de 80 , quando surgiu o dramático problema da contaminação pelo vírus do HIV, detectado no sangue de hemofílicos que receberam crioprecipitado plasmático. A partir daí iniciaram-se inúmeras pesquisas com o objetivo de introduzir novos produtos na terapêutica da hemofilia. ${ }^{3-12}$

${ }^{1}$ Doutora. Dept ${ }^{\circ}$ Ciências Biológicas - Faculdade de Ciências - Bauru - Unesp.

${ }^{2}$ Doutora. Dept ${ }^{\circ}$ Urologia - Hemocentro de Botucatu - Faculdade de Medicina - Unesp.

${ }^{3}$ Doutora. Laboratório de Hemostasia - Hemocentro de Botucatu - Unesp.

${ }^{4}$ Doutor. Professor titular do Dept ${ }^{\circ}$ de Clínica Médica Faculdade de Medicina - Botucatu - Unesp.

Correspondência: Rosana Rossi Ferreira

Hemocentro, FMB, Unesp

Distrito de Rubião Júnior, $s / n$

18618-970 - Botucatu-SP - Brasil

Fax: +55-14-3801-6041

E-mail: rossi@fc.unesp.br 
As novas técnicas de engenharia celular e biotecnologia avançaram muito nas últimas décadas e entre elas a produção de anticorpos monoclonais utilizados tanto para o aprimoramento diagnóstico em rotinas laboratoriais como na produção de medicamentos e purificação de proteínas utilizadas na terapêutica. ${ }^{13-17}$ Os concentrados de FVIII purificados através de anticorpos monoclonais (denominados produtos ultrapuros) colocados no mercado no início dos anos 90 vieram solucionar complicações desastrosas no tratamento da hemofilia, pois se trata de terapêutica eficaz e segura apresentando alta especificidade, segurança viral e redução de efeitos colaterais. Porém estes produtos só podem ser adquiridos no mercado internacional a um custo bastante elevado, pois inexiste no Brasil a produção destes anticorpos voltados a esta finalidade. É objetivo deste trabalho a obtenção de anticorpos monoclonais murinos, purificação e posterior adsorção em coluna de imunoafinidade para obtenção de concentrado de fator VIII ultrapuro.

\section{Materiais e Métodos}

\section{Animais e imunização}

Utilizamos camundongos da linhagem isogênica BALB/c. As imunizações foram realizadas através da inoculação de fator VIII purificado (Koate ${ }^{\circledR}$ Cutter 250UI $5 \mathrm{ml}$ ) e fator VIII proveniente de bolsa de crioprecipitado, ambos por via intraperitoneal. Nos dois protocolos (I e II respectivamente) foi utilizado adjuvante de imunização $\operatorname{KAl}\left(\mathrm{SO}_{4}\right)_{2}(0,2 \mathrm{~g} / \mathrm{ml}) .{ }^{25}$

\section{Fusão celular}

As fusões celulares foram realizadas segundo o método descrito por Kohler \& Milstein ${ }^{18}$ utilizando como parceiro de fusão mieloma múltiplo murino $\left(\mathrm{NS}_{1}\right)$ e linfócitos B retirados do baço dos animais previamente imunizados. A seleção enzimática dos híbridos obtidos (hibridomas) foi realizada dentro do sistema hipoxantina-guanina-fosforibosiltransferase (HGPRT).

\section{Screening dos híbridos obtidos}

O método de escolha para o screening dos híbridos obtidos foi a quantificação de inibidores de FVIII com resultados expressos em Unidades Bethesda (Ubeth). ${ }^{19}$

\section{Clonagem dos híbridos secretores}

A partir da determinação da viabilidade celular através da coloração com azul de trípano a $0,3 \%$, a clonagem foi realizada pelo método da diluição limitante..$^{20,21}$

Produção de líquido ascítico

Este procedimento foi realizado com o objetivo de se obterem concentrações dez vezes maiores que as obtidas com os sobrenadante da cultura. ${ }^{22}$

Foi injetado $1 \mathrm{ml}$ de óleo mineral puro por via intra- peritoneal em camundongos com idade entre 2 a 3 meses. Após 10-14 dias, injetou-se $1 \mathrm{ml}$ de meio de cultura contendo $5 \times 10^{5}$ a $5 \times 10^{6}$ células pela mesma via. Os animais foram observados diariamente quanto ao crescimento do abdômen. Após uma a duas semanas, o líquido acumulado foi puncionado.

A classe e subclasse das imunoglobulinas foram determinadas por citometria de fluxo utilizando-se anticorpos de especificidade conhecida como Rabbit Anti -IgM Mouse (ICN Biomedicals ${ }^{\circledR}$ ) and Goat Anti-IgG Mouse (Serotec U.K. $\left.{ }^{\circledR}\right)$

\section{Eletroforese em SDS-PAGE}

Foram utilizadas as seguintes fontes de FVIII: 1Koate ${ }^{\circledR}$, 2-Octavi ${ }^{\circledR}$, 3-Biotest SDH ${ }^{\circledR}$, 4-Crioprecipitate. Os concentrados protéicos foram separados em gel de poliacrilamida (PAGE) utilizando tampão contendo dodecil sulfato de sódio (SDS) e analisados através de programa de análise de imagem (VDS® Amersham Pharmacia Biotech) para determinação dos pesos moleculares.

\section{Immunoblotting}

Bandas de diferentes pesos moleculares definidas na proteína FVIII através de eletroforese SDS-PAGE foram transferidas para membrana de nitrocelulose $0,45 \mu$ (Gibco BRL $\left.{ }^{\circledR}\right)^{23}$ e incubadas com o AcMm overnight. Após lavagem, a membrana foi incubada com anticorpo secundário Rabbit anti-IgG mouse conjugado com peroxidase (Nordic ${ }^{\circledR}$ Immunological).

Purificação em proteína A sefarose

O líquido ascítico foi incorporado à matriz de proteína A sefarose CL-4B (Amersham Pharmacia Biotech ${ }^{\circledR}$ ) e eluído através da passagem de tampões com diferentes pHs.

Adsorção em coluna de imunoafinidade

Utilizamos como matriz de acoplamento sefarose $\mathrm{CNBr}$ (Amersham Pharmacia Biotech ${ }^{\circledR}$ ) ativada que recebeu $15 \mathrm{mg} / \mathrm{ml}$ de imunoglobulina. O concentrado de fator VIII (crioprecipitado) desprovido de plasma e tratado com Tris- $\mathrm{HCl}$ 0,02M pH 6.7 acrescido de heparina 3UI/ml e $\mathrm{Al}(\mathrm{OH})_{3}$ foi aplicado sobre o gel. 22,24

\section{Resultados}

Os protocolos de fusões celulares realizados segundo método descrito por Kohler \& Mistein ${ }^{18}$ estão descritos na tabela 1. Os híbridos obtidos foram submetidos ao teste de screening no qual foi escolhido o método de quantificação de inibidores do fator VIII, e os valores obtidos foram expressos em Unidades Bethesda (Ubeth). O resultado do screening apontou para uma separação dos híbridos obtidos de acordo com a reatividade apresentada pelos mesmos. Esta reatividade indica a capacidade secretora dos hibridomas 
Tabela 1

Eficiência das fusões celulares nos protocolos de imunização utilizando como antígeno fator VIII concentrado comercial

\begin{tabular}{cccccc}
\hline $\begin{array}{c}\text { Fusão } \\
\text { (Protocolos) }\end{array}$ & $\begin{array}{c}\mathrm{N}^{\circ} \text { de } \\
\text { placas }\end{array}$ & $\begin{array}{c}\mathrm{N}^{\circ} \mathrm{de} \\
\text { híbridos } \\
\text { distribuídos }\end{array}$ & $\begin{array}{c}\mathrm{N}^{\circ} \text { de } \\
\text { híbridos } \\
\text { obtidos }\end{array}$ & $\begin{array}{c}\mathrm{N}^{\circ} \text { de } \\
\text { híbridos } \\
\text { testados }\end{array}$ & $\begin{array}{c}\text { Eficiência de } \\
\text { fusão (\% }\end{array}$ \\
\hline $\begin{array}{c}\text { LAMB 1 } \\
2 \text { animais }\end{array}$ & 10 & 960 & 651 & 292 & 67,8 \\
$\begin{array}{c}\text { LAMB 2 } \\
4 \text { animais }\end{array}$ & 21 & 2016 & 1461 & 960 & 72,6 \\
\hline
\end{tabular}

Tabela 2

Diferentes reatividades apresentadas pelos híbridos secretores de imunoglobulinas anti-fator VIII medidas através do método de quantificação de inibidores de fator VIII expressos em Unidades Bethesda/ml (UBeth/mL)

\begin{tabular}{ccccc}
\hline $\begin{array}{c}\text { Fusão } \\
\text { (Protocolos) }\end{array}$ & $\begin{array}{c}\text { N}^{\circ} \text { de } \\
\text { híbridos } \\
\text { positivos }\end{array}$ & $\begin{array}{c}\text { Baixa } \\
\text { reatividade } \\
0,6-1,5 \\
\text { UBeth/ml }\end{array}$ & $\begin{array}{c}\text { Reatividade } \\
\text { mediana } \\
1,5-4,0 \\
\text { UBeth/ml }\end{array}$ & $\begin{array}{c}\text { Alta } \\
\text { reatividade } \\
4,0-8,0 \\
\text { UBeth/ml }\end{array}$ \\
\hline $\begin{array}{c}\text { LAMB 1 } \\
2 \text { animais }\end{array}$ & 25 & 11 & 13 & 01 \\
$\begin{array}{c}\text { LAMB 2 } \\
4 \text { animais }\end{array}$ & 71 & 11 & 19 & 41 \\
\hline
\end{tabular}

Tabela 3

Resultado das clonagens realizadas a partir de híbridos selecionados.

\begin{tabular}{|c|c|c|c|c|}
\hline Hîbridos & Viabilidade & $\begin{array}{l}\mathrm{N}^{\circ} \mathrm{de} \\
\text { clones } \\
\text { obtidos } \\
\end{array}$ & $\begin{array}{c}\mathrm{N}^{\mathrm{o}} \text { de clones } \\
\text { positivos no } \\
\text { screening }\end{array}$ & Clones selecionados \\
\hline LAMB 1-10 & $<98 \%$ & 13 & 08 & $\begin{array}{l}\text { LAMB1-10A1A2 } \\
\text { LAMB1-10A1A4 } \\
\text { LAMB1-10A1A6 } \\
\text { LAMB1-10A1A7 } \\
\text { LAMB1-10A1A8 } \\
\text { LAMB1-10A1A9 } \\
\text { LAMB1-10A1A10 } \\
\text { LAMB1-10A4A1 }\end{array}$ \\
\hline LAMB 1-17 & $<95 \%$ & 25 & 07 & $\begin{array}{l}\text { LAMB1-17A1A1 } \\
\text { LAMB1-17A1A2 } \\
\text { LAMB1-17A1A3 } \\
\text { LAMB1-17A1A4 } \\
\text { LAMB1-17A4A2 } \\
\text { LAMB1-17A4A8 } \\
\text { LAMB1-17A4A10 }\end{array}$ \\
\hline LAMB 1-24 & $<92 \%$ & 14 & 05 & $\begin{array}{l}\text { LAMB1-24 A1A3 } \\
\text { LAMB1-24 A2A1 } \\
\text { LAMB1-24 A2A4 } \\
\text { LAMB1-24A2A5 } \\
\text { LAMB1-24A2A9 }\end{array}$ \\
\hline LAMB 2-8 & $<95 \%$ & 29 & 08 & $\begin{array}{l}\text { LAMB2-8 A2 } \\
\text { LAMB2-8 A3 } \\
\text { LAMB2-8 A5 } \\
\text { LAMB2-8 A12 } \\
\text { LAMB2-8 A20 } \\
\text { LAMB2-8 A24 } \\
\text { LAMB2-8 A27 } \\
\text { LAMB2-8 A29 }\end{array}$ \\
\hline
\end{tabular}

selecionados. A tabela 2 mostra a separação de acordo com a reatividade compreendida em faixas de Unidades Bethesda e o número de hibridomas encontrados em cada faixa. Um segundo teste de screening, agora somente com os híbridos de alta reatividade, foi realizado uma semana após o primeiro para se confirmar a manutenção da especificidade. As células que tiveram sua especificidade confirmada foram expandidas em cultura para clonagem. Foram clonadas somente células com viabilidade celular superior a 90\%. ${ }^{21}$ A tabela 3 mostra os híbridos submetidos à clonagem e os híbridos selecionados por manterem a especificidade em novo screening realizado.

Clones que apresentaram expansão satisfatória em cultura foram inoculados no peritônio dos animais para produção de líquido ascítico. Após a coleta, foi realizado o controle da monoclonalidade através de eletroforese em gel de agar. Todos os clones apresentaram pico monoclonal, embora com intensidades diferentes (Figura 1). Posteriormente foram submetidos à caracterização quanto à classe e subclasse da imunoglobulina através da citometria de fluxo. Os resultados estão ilustrados na tabela 4.

Para a caracterização imunoquímica foi realizado o immunoblotting com a transferência das frações visualizadas na eletroforese em gel de poliacrilamida (SDS-PAGE) proveniente de três produtos comerciais e também do crioprecitpitado plasmático (FVIII in natura) e posterior incubação com as imunoglobulinas secretadas pelos clones. Para realizar uma análise mais precisa dos pesos moleculares em relação às frações obtidas na eletroforese, utilizamos o programa VDS ${ }^{\circledR}$ de análise de imagem.

A figura 2 mostra a eletroforese dos produtos analisados e o immunoblotting do clone LAMB1-10A1A4. De acordo com a análise de imagem feita pelo programa VDS ${ }^{\circ}$ (dados não mostrados) observa-se que o anticorpo secretado reconheceu a fração de $250 \mathrm{kDa}$ identificada em todos os produtos de FVIII transferidos para a membrana de nitrocelulose. Também reconheceu frações de 160 kDa (Crio e Biotest ${ }^{\circledR}$ ), 88 kDa (Biotest ${ }^{\circledR}$ ) e ainda frações de 40 e 50 kDa em todos os produtos.

A figura 3 mostra as frações reconhecidas pela imunoglobulina secretada pelo clone LAMB117A1A1 cuja análise das imagens mostra o reconhecimento também da fração de 250 kDa e frações de 40 e $50 \mathrm{kDa}$. O clone LAMB1-24A2A1 também reconheceu as mesmas frações dos clones anteriores (Figura 4). 
Tabela 4

Determinação da classe e subclasse dos clones obtidos nos protocolos LAMB1 e LAMB2 por citometria de fluxo

\begin{tabular}{cc}
\hline Clone & Classe e subclasse \\
\hline LAMB1-10A1A4 & $\operatorname{lgG}_{1}$ \\
LAMB1-17A1A1 & $\operatorname{lgG}_{\mathrm{b}}$ \\
LAMB1-24A2A1 & $\operatorname{lgG}_{3}$ \\
LAMB2-8A2 & $\operatorname{lgG}_{3}$ \\
LAMB2-8A5 & $\operatorname{lgG}_{3}$ \\
LAMB2-8A20 & $\operatorname{lgG}_{3}$ \\
LAMB2-8A29 & $\operatorname{lgG}_{3}$ \\
\hline
\end{tabular}

As figuras 5, 6, 7 e 8 mostram a corrida eletroforética dos três concentrados de Fator VIII comerciais juntamente com o immunoblotting dos clones do protocolo LAMB2.

O anticorpo monoclonal LAMB2-8A2 (Figura 5) reconheceu uma fração de 89 kDa (produto Biotest ${ }^{\circledR}$ ), LAMB2-8A5 (Figura 6) reconheceu frações de 250kDa, (nos três produtos) e $60 \mathrm{kDa}$ (Biotest ${ }^{\circledR}$ e Koate $\left.{ }^{\circledR}\right)$.

O anticorpo monoclonal LAMB2-8A20 (Figura 7) reconheceu fração de 250 kDa e fração entre 70 e 80 kDa nos três produtos analisados.

O anticorpo LAMB2-8A29 (Figura 8) reconheceu frações de peso molecular entre 180 e 90 kDa somente do produto Biotest ${ }^{\circledR}$.

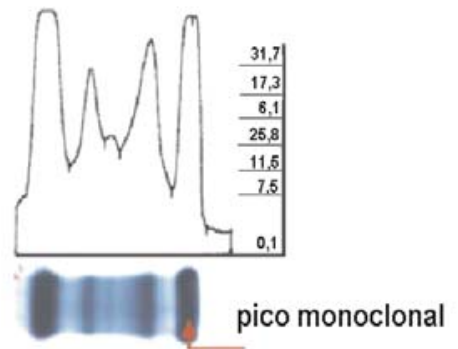

LAMB1-10A1A4

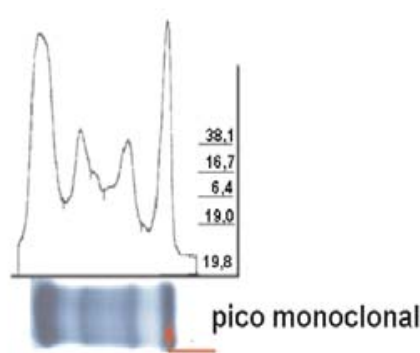

LAMB1-17A1A1

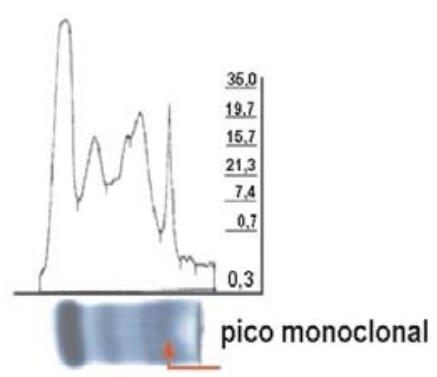

LAMB1-24A2A1

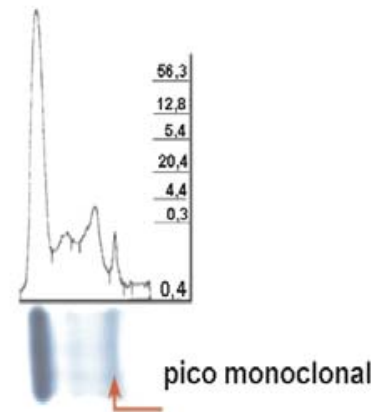

LAMB2-8 A2

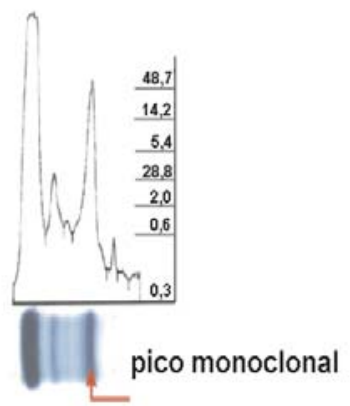

LAMB2-8 A5

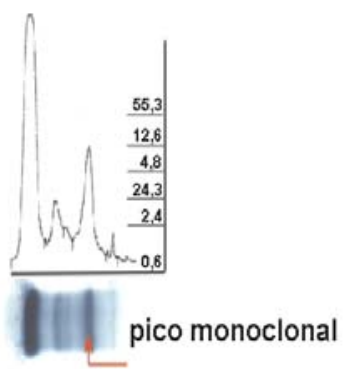

LAMB2-18 A20

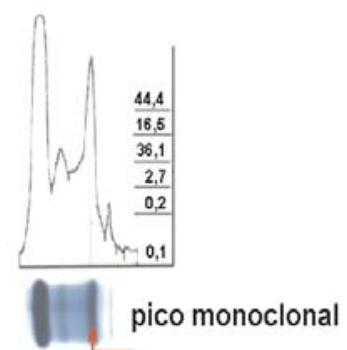

LAMB2-8 A29

Figura 1. Eletroforese em gel de ágar 1\% de líquido ascítico de camundongo BALB/c. Coloração negro de amido

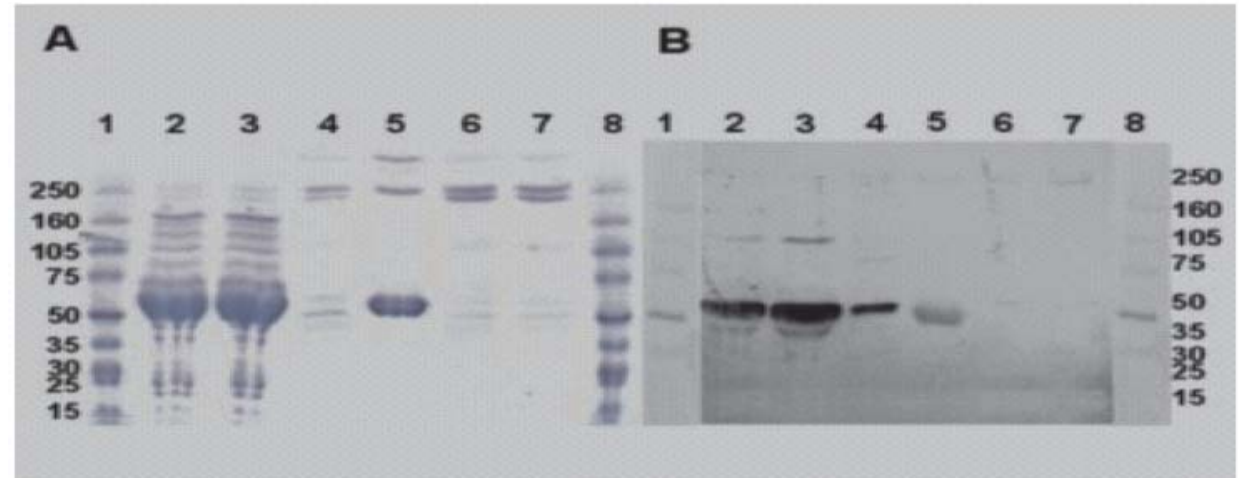

Figura 2. Eletroforese SDS-PAGE - gradiente 4\%-15\% (A) e immunoblotting do AcMm produzido pelo clone LAMB1-10 A1A4 contra fator VIII (B).

A). Pistas 1 e 8 - Marcador de peso molecular (Rainsbow® Pharmacia); Pistas 2 e 3 - FVIII crioprecipitado; Pista 4 - FVIII Biotest $₫$; Pista 5-FVIII Koate ${ }^{\circledR}$; Pistas 6 e 7 FVIII Octavi ${ }^{\circledR}$

B) Pistas 1 e 8 - Marcador de peso molecular (Rainsbow® Pharmacia); Pista $2 \mathrm{e}$ 3 - Crioprecipitado; Pista 4 - FVIII Biotest $₫$; Pista 5 - FVIII Koate $®$; Pista 6 e 7 - fator VIII Octavi® 


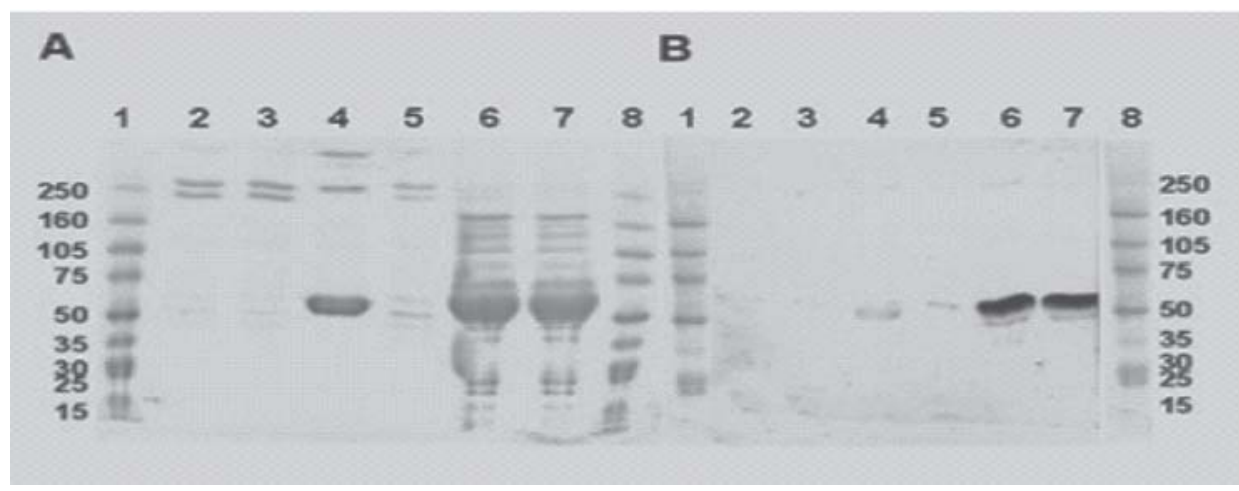

Figura 3. Eletroforese SDS-PAGE gradiente 4\%-15\% (A) e immunoblotting do AcMm produzido pelo clone LAMB117A1A1 contra fator VIII

A) Pistas 1 e 8 - Marcador de peso molecular (Rainsbow $®$ Pharmacia); Pistas 2 e 3 -FVIII Octavi®; Pista 4 - FVIII Koate $₫$; Pista 5 - FVIII Biotest $₫$; Pistas 6 e 7 - FVIII crioprecipitado.

B) Pistas 1 e 8 - Marcador de peso molecular (Rainsbow $®$ Pharmacia); Pista 2 e 3 - Octavi ${ }^{\circledR}$; Pista 4 - FVIII Biotest $₫$; Pista 5 - FVIII Koate ${ }^{\circledR}$; Pista 6 e 7 - fator VIII crioprecipitado

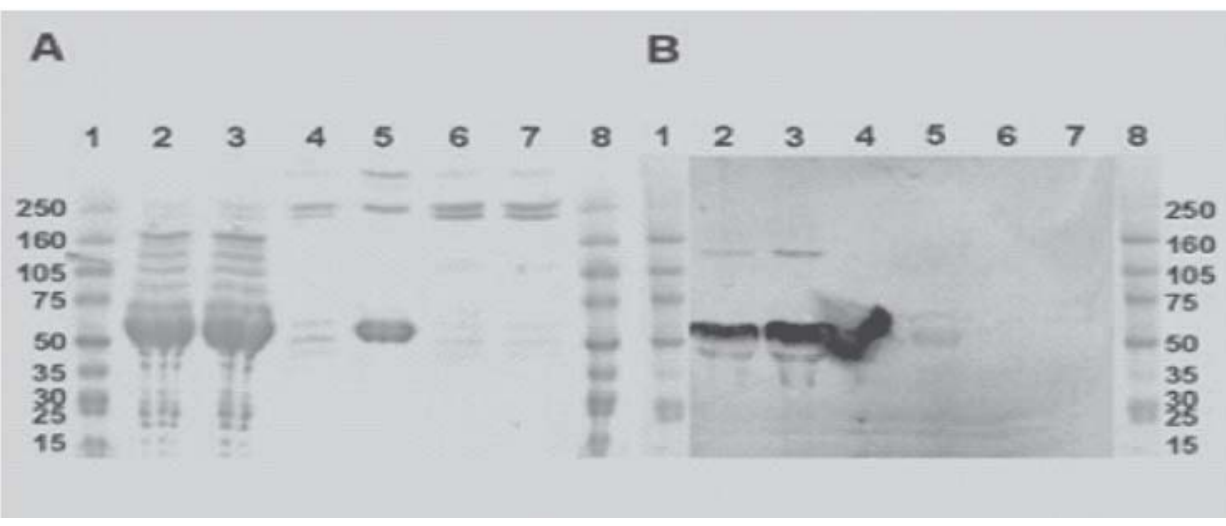

Figura 4. Eletroforese SDS-PAGE gradiente $4 \%-15 \%$ e immunoblotting do AcMm produzido pelo clone LAMB1-24 A2A1 contra fator VIII

A) Pistas 1 e 8 - Marcador de peso molecular (Rainsbow $₫$ Pharmacia); Pistas 2 e 3 - FVIII crioprecipitado; Pista 4 - FVIII Biotest $\AA$; Pista 5 - FVIII Koate $®$; Pistas 6 e 7 - fator VIII Octavi ${ }^{\circledR}$

B) Pistas 1 e 8 - Marcador de peso molecular (Rainsbow ${ }^{\circledR}$ Pharmacia); Pista 2 e 3-Crioprecipitado; Pista 4-FVIII Biotest $₫$; Pista 5 - FVIII Koate ${ }^{\circledR}$; Pista 6 e 7 - fator VIII Octavi®

Figura 5. Eletroforese SDS-PAGE gradiente $4 \%-15 \%$ e immunoblotting do AcMm produzido pelo clone LAMB2$8 \mathrm{~A} 2$ contra fator $\mathrm{VIII}$

A) Pistas 1 e 8-Marcador de peso molecular (Rainsbow ${ }^{\circledR}$ Pharmacia); Pistas 2 e 3 - FVIII Koate ${ }^{\circledR}$; Pistas 4 e 5 - FVIII Biotest $₫$; Pistas 6 e 7-FVIII Octavi $\circledast$

B) Pistas 1 e 5 - Marcador de peso molecular (Rainsbow® Pharmacia); Pista 2 - FVIII Koate $₫$; Pista 3 - FVIII Biotest $₫$, Pista 4 - FVIII Octavi®

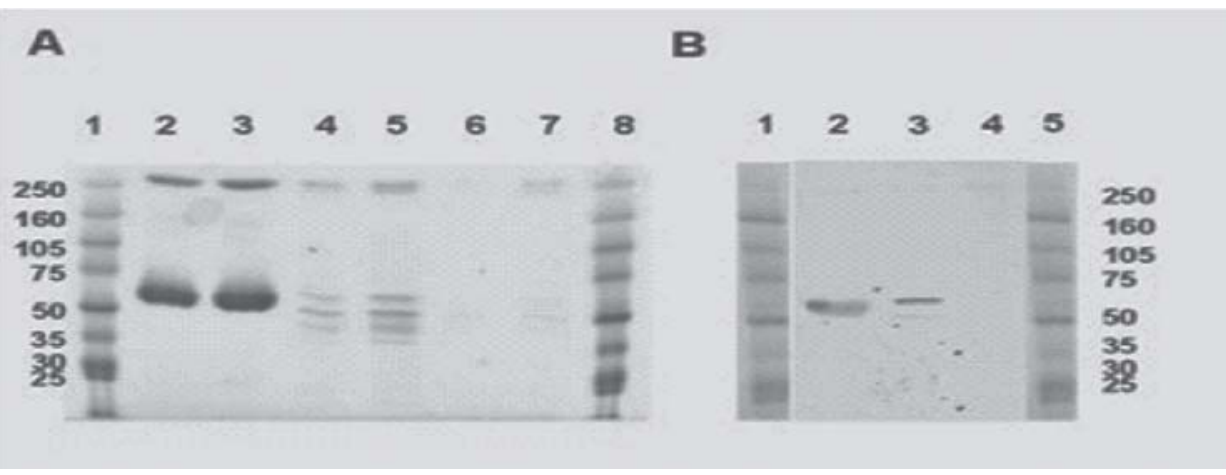

Figura 6. Eletroforese SDS-PAGE gradiente 4\%-15\% e immunoblotting do AcMm produzido pelo clone LAMB28A5 contra fator VIII

A) Pistas 1 e 8-Marcador de peso molecular (Rainsbow ${ }^{\circledR}$ Pharmacia); Pistas 2 e 3 - FVIII Koate $\AA$; Pistas 4 e 5 - FVIII Biotest $₫$; Pistas 6 e 7 - FVIII Octavi ${ }^{\circledR}$

B) Pistas 1 e 5-Marcador de peso molecular (Rainsbow ${ }^{\circledR}$ Pharmacia); Pista 2 - FVIII Koate $₫$; Pista 3 - FVIII Biotest $₫$; Pista 4 - fator VIII Octavi ${ }^{\circledR}$ 

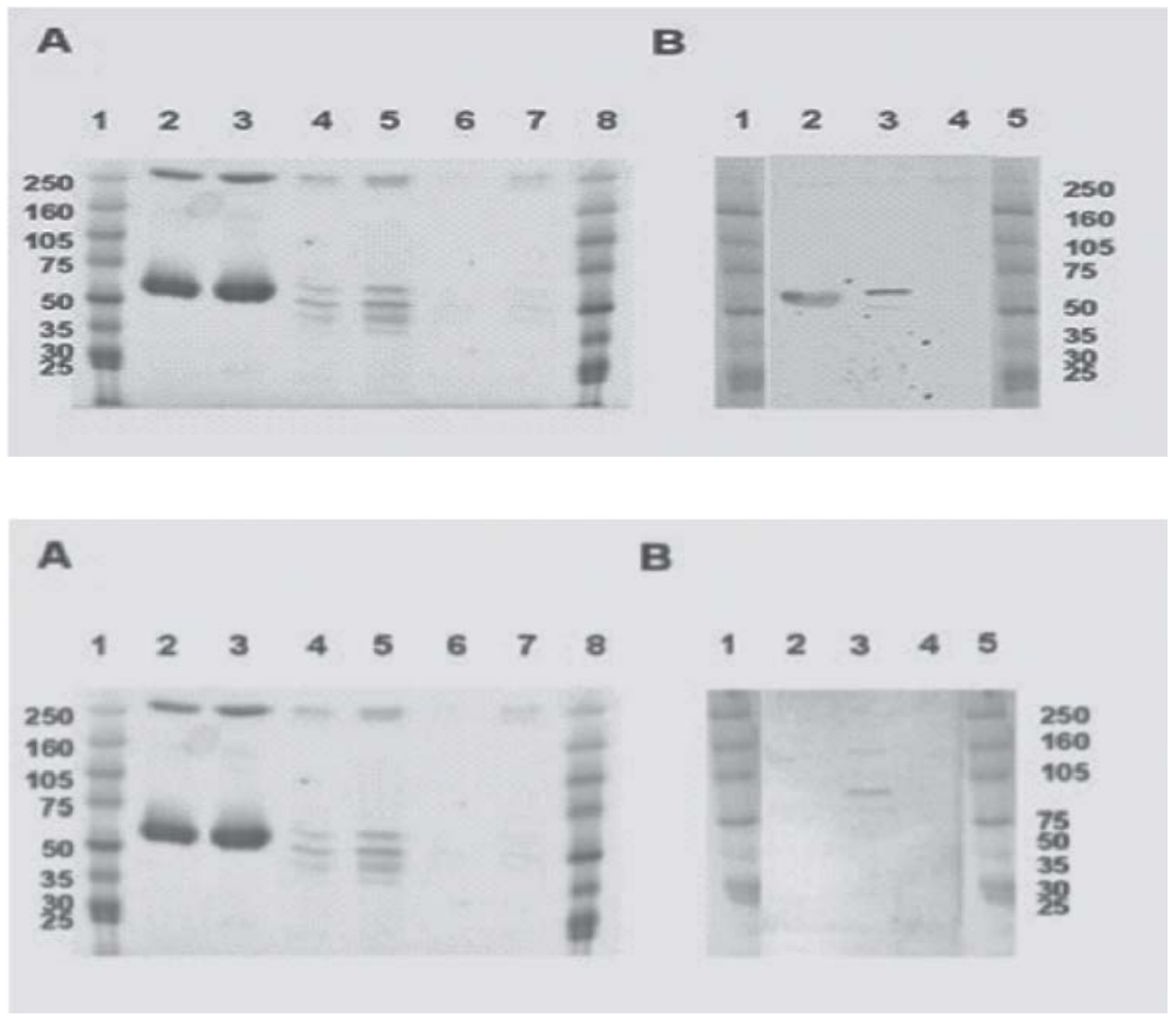

Figura 7. Eletroforese SDS - PAGE gradiente $4 \%-15 \%$ e immunoblotting do AcMm produzido pelo clone LAMB2$8 \mathrm{~A} 20$ contra fator VIII

A) Pistas 1 e 8 - Marcador de peso molecular (Rainsbow ${ }^{\circledR}$ Pharmacia); Pistas 2 e 3 FVIII Koate $\circledast$; Pistas 4 e 5 - FVIII Biotest $\AA$; Pistas 6 e 7-FVIII Octavi

B) Pistas 1 e 5 - Marcador de peso molecular (Rainsbow ${ }^{\circledR}$ Pharmacia); Pista 2 - FVIII Koate $₫$; Pista 3 - FVIII Biotest $₫$; Pista 4 - fator VIII Octavi®
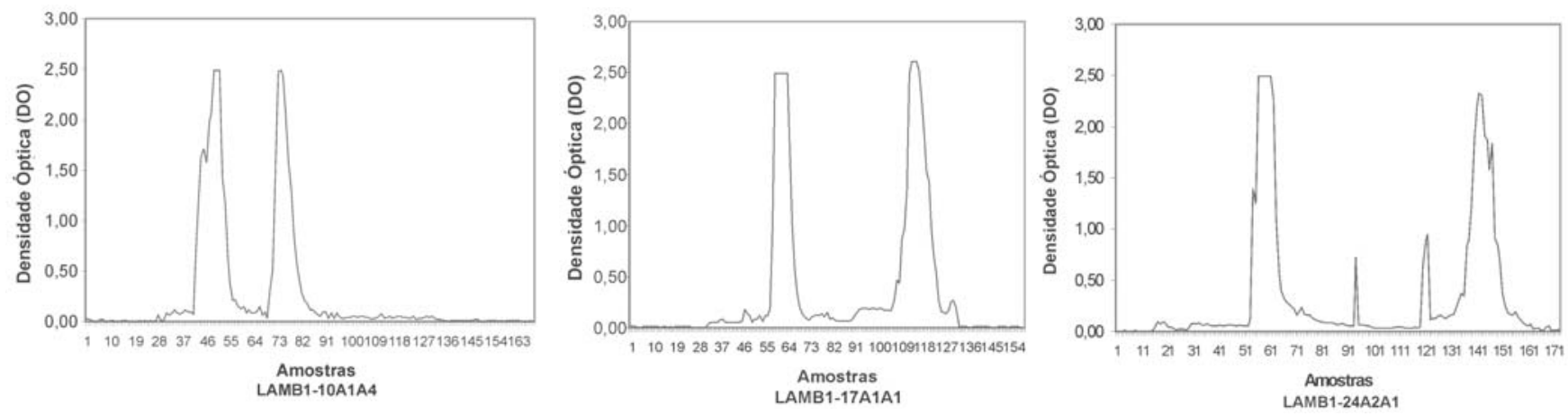

Figura 9. Purificação dos clones LAMB1-10A1A4, LAMB1-17A1A1 e LAMB1-24A2A1 em coluna de proteínaA sefarose

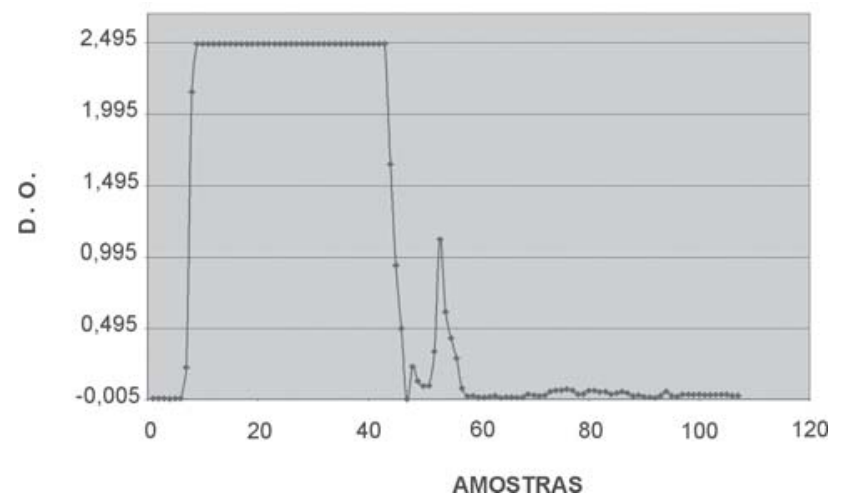

Figura 10. Purificação do fator VIII através do AcMm LAMB1-10A1A4 adsorvido na matriz de acoplamento do tipo Sephadex-CNBr-ativated
Figura 8. Eletroforese SDS-PAGE gradiente $4 \%-15 \%$ e immunoblotting do AcMm produzido pelo clone LAMB28 A29 contra fator VIII

A) Pistas 1 e 8-Marcador de peso molecular (Rainsbow ${ }^{\circledR}$ Pharmacia); Pistas 2 e 3 FVIII Koate ${ }^{\circledR}$; Pistas 4 e 5 - FVIII Biotest $₫$; Pistas 6 e 7- FVIII Octavi ${ }^{\circledR}$ B) Pistas 1 e 5-Marcador de peso molecular (Rainsbow ${ }^{\circledR}$ Pharmacia); Pista 2 - FVIII Koate $®$; Pista 3 - FVIII Biotest $₫$; Pista 4 -FVIII Octavi® 


\section{Discussão}

Frente aos resultados obtidos no immunoblotting verificamos que nos concentrados comerciais utilizados como fonte de fator VIII, os anticorpos monoclonais produzidos pelos três clones selecionados do protocolo LAMB1 são dirigidos tanto para a fração de maior peso molecular (antes da molécula de fator VIII sofrer clivagem proteolítica pela trombina) como a fração de menor peso molecular (resultante do processo proteolítico). Vale notar que os anticorpos monoclonais reconheceram somente epítopos pertencentes à molécula de fator VIII, pois a fração de $60 \mathrm{kDa}$ presente nos três produtos, que provavelmente refere-se à albumina, não foi reconhecida pelos anticorpos monoclonais. Este fato é devido ao screening realizado, onde foram retidos somente clones secretores de anti-fator VIII, mas muito provavelmente o animal deve ter respondido com imunoglobulinas contra outras proteínas, entre elas a albumina, devido a sua grande quantidade nos produtos utilizados para imunização. A albumina é utilizada no processo de purificação desses concentrados para estabilizar a molécula de fator VIII, uma glicoproteína de $265 \mathrm{kDa}$ extremamente sensível à clivagem..$^{27,28,29}$ A produção de antialbumina já tem sido motivo de estudos em nosso laboratório. No concentrado proveniente do crioprecipitado, os anticorpos monoclonais também foram hábeis em reconhecer fração de tamanho intermediário de $160 \mathrm{kDa}$ e $70 \mathrm{kDa}$. Isto pode significar que estas imunoglobulinas frente a concentrados plasmáticos ricos em FVIII reconhecem epítopos que representam porções mais ativas do fator anti-hemofílico como a fração de $70 \mathrm{kDa} .{ }^{29}$ Isto contribui, sobremaneira, para a utilização dos clones em processos de purificação na obtenção de concentrados de fator VIII de alta pureza. Os anticorpos monoclonais oriundos do protocolo LAMB2 analisados mostraram o reconhecimento de epítopo que provavelmente representa a fração ativa do fator VIII (FVIII:C) com peso molecular em torno de $70 \mathrm{kDa}$. Esse reconhecimento foi mais freqüente sobre as frações obtidas com o produto da Biotest ${ }^{\circledR}$. Isto pode significar que os concentrados purificados de fator VIII comerciais apresentam diferenças no processo de manufaturação, o que pode promover modificações conformacionais na molécula do FVIII, ${ }^{26}$ fato que explicaria o reconhecimento das frações ter recaído mais sobre o concentrado comercial Biotest ${ }^{\circledR}$, lembrando que a fonte imunogênica foi o crioprecipitado, onde podemos dizer que a proteína fator VIII encontra-se em seu estado in natura, ou seja, isenta de qualquer processo de manufaturação industrial como a purificação. Quando foram transferidas para membrana de nitrocelulose as frações obtidas na separação por eletroforese do crioprecipitado, observamos que todos os anticorpos monoclonais oriundos do protocolo que tiveram como estímulo imunogênico o próprio crioprecipitado fizeram o reconhecimento de maneira mais uniforme.

\section{Abstract}

Among the advances in cellular engineering and biotechnology over the last decades, the production of murine monoclonal antibodies (AcMm), used to improve laboratory diagnoses, stands out. The production of very pure factor VIII has always been a concern of suppliers of blood products to treat patients with hemophilia A and this product is still not produced in Brazil. Hence, it can only be attained on the international market at a high cost. The aim of this work was to produce AcMm anti-factor VIII human (FVIIIh) by expanding clones and characterizing the antibodies by immunochemistry. Balb/c mice were immunized with FVIII both purified and from cryoprecipitation and the splenic cells of the animals were fused with myelomatous murine cells according to the method described by Kohler and Milstein to produce hybrids in a culture. A total of 1983 hybrids were tested and 105 were selected for cloning. Of these, 39 developed monoclonality and 7 of these clones were characterized through immunoblotting techniques. Three immunoglobulins from different classes, LAMB110A1A4, LAMB1-17A1A1 and LAMB1-24A2A1, were submitted to chromatography for purification. The purified immunoglobulin from the LAMB1-10A1A4 clone was adsorbed in the immunoaffinity column to purify the factor VIII concentrate coming from the plasmatic cryoprecipitate. Rev. bras. hematol. hemoter. 2006; 28(2):97-104.

Key words: Factor VIII; monoclonal antibodies; hemophilia; blood derivatives; biotechnology.

\section{Agradecimentos}

Somos gratos a Srta. Fátima Regina Guimarães pelo apoio técnico na realização das culturas celulares.

\section{Referências Bibliográficas}

1. Pool P, Robinson R. Observation on plasma banking and transfusion procedure for haemophilic patients using a quantitative assay for antihaemophilic globulin (AHG). British Journal Haematology 1959;5: 24-30.

2. Cohn EJ, Strong LE, Hugues WL. Preparation and properties of serum and plasma protein. A system for the separation into fractions of the protein and lipoprotein components of biological tissues and fluids. Journal American Chemistry Society 1946;68:459.

3. Rotblat F, O'Brien D, Goodall A, Tuddenham EGD. Purification of human factor VIII: C and its characterization by Western Blotting using monoclonal antibodies. Biochemistry 1985;24:4294.

4. Foster PR, McIntoch RV. The manufacture of factor VIII concentrate. Transfusion 1991;31(6):573.

5. Morfini M, Messori A, Longo G, Cinotti S, Matucci M, Rossi-Ferreini P. Halflife and in vivo recovery of heated factor VIII. Lancet 1986; II, p. 571-2.

6. Messori A, Longo G, Matucci M, Morfini M, Rossi-Ferrini P, Cianotti $\mathrm{S}$, et al. Clinical pharmacokinetics of factor VIII in patients with classic hemophilia. Clinical Pharmacokinetic 1987;13:365-80.

7. Morfini M, Mannucci PM, Longo G, Cinotti S, Messori A. Comparative evaluation of the pharmacokinetics of three monoclonal factor VIII concentrate. Thrombosis Haemostasis 1991;61:85-90.

8. Morfini M. In vitro characteristics of highly purified factor VIII concentrate. Annals of Hematology 1991;63:123-25. 
9. Kasper CK, Kim HC, Gomperts ED, Smith KJ, Salzman PM,Tipping D, et al. In vivo recovery and survival of monoclonal-antibody-purified factor VIII concentrates. Thrombosis Research 1991;66(6):730-3.

10. Morfini M, Mannucci PM, Tenconi PM, Longo G, Mazzucconi MG, Rodeghiero F et al. Pharmacokinetics of monoclonal-purified and recombinant factor VIII in patients with severe von Willebrand disease. Thrombosis Research 1993; 70 (2): 270-2.

11. Schuman S. Effects of factor VIII concentrates on the immune system in hemophilic patients. Annals os Hematology 1991;63:145-51.

12. Gomperts ED . Antihemophilic factor isolated with monoclonal antibodies. Annals of Hematology 1991;63:142-144.

13. Lusher JM. Viral safety and inhibitor development associated with monoclonal antibody-purified FVIII: C. Annals of Hematology 1991;63: 138-41.

14. Smid WM, Van der Meer J, Halie MR. Efficacy and safety of a monoclonal purified factor VIII concentrate: 5-year follow-up in previously treated HIV-negative haemophiliacs. Haemostasis 1995;25: 229-236.

15. Gordon E, Al-Batniji F, Golsmith J. Continuous infusion of monoclonal antibody-purified factor VIII: rational approach to serious hemorrhage in patients with allo-autoantibodies to factor VIII. American Journal of Hematology 1994;45:142-145.

16. De Geus B, Hendriksen CFM. In vivo and production of monoclonal antibodies: current possibilities and future perspectives. Research Immunology 1998;119:533-4.

17. Chen C, Fang XD, Zhu I, Wu XF, Zhang ZC, Gu JX, et al. The gene expression of coagulation factor VIII in mammalian cell lines. Thrombosis Research 1999;95(2):105-115.

18. Kohler G \& Milstein C. Continuous cultures of fused cells secreting antibody of predefined specificity. Nature 1975;256(7):495-497.

19. Kasper K, Alendort LM, Counts RB, Edson JR, Fratantoni J, Green D, et al. A more uniform measurement of factor VIII inhibitors. Thrombosis Diathesis Haemorrhagie 1975;34:869-871.

20. Catty D \& Raykundalia C. Immunodifusion, immunoeletrophoresis and immunostaining. In: Catty, D. Antibodies: a practical approach. Washington: IRL Press, v.1, cap.6, p.137-167. 1988.
21. Davis JN. Basic cell culture: a practical approach. Oxford: IRL Press, 301p. 1994.

22. Deffune E. Obtention dánticorps monoclonaux murins diriges contre le troisienne composant du complement. Interet in immunohematologie. Doctoral thesis, Université Pierre er Marie Currie-IV, Paris. 1992.

23. Towbin H, Stachelin T, Gordon J. Electrophoretic transfer of protein from polyacrilamide gels to nitrocellulose sheets: Procedure and some application. Proceeding of National Academy of Science, USA, 1979; 76: 4.350-4.354.

24. Rossi-Ferreira R. Obtenção de anticorpo monoclonal murino anti-fator VIII da coagulação sangüínea. Doctoral thesis. Faculdade de Medicina, Unesp, Botucatu, Brazil. 2001.

25. Davis JN. Basic cell culture: a practical approach. Oxford: IRL Press, 301p. 1994.

26. Fulcher C, Roberts JR, Zimmerman T. Thrombin proteolysis of purified factor VIII procoagulant protein; correlation of activation with generation of a specific polypeptide. Blood 1983;61(4): 807-811.

27. Scandella D, Gilbert GE, Shima M, Nakai H, Eagleson C, Felch M, et al. Some factor VIII inhibition antibodies recognize a common epitope corresponding to C2 domain Amino Acids 2248 through 2312 which overlap a phospholipid-binding site. Blood 1995;86(5):1.811-1.819.

28. Pitman DD, Kaufman RJ. Proteolytic requirements for thrombin activation of antihemophilic factor (factor VIII). Proceeding of the National Academy of Science, USA, 1988;85:2.429-2.433.

29. Fay PJ, Haidaris PJ, Smudzin TM. Human factor VIIIa subunit structure. Journal of Biology and Chemistry 1991;266(14):8.957-8.962.

Avaliação: Editor e dois revisores externos.

Conflito de interesse: não declarado

Recebido: 06/12/2005

Aceito após modificações: 17/02/2006

Recursos financeiros: Pesquisa financiada por Finep. 